\title{
Argentina: gobernabilidad y movimientos sociales. El caso del Movimiento Nacional de Empresas Recuperadas
}

\author{
Argentina: governance and social movements. \\ The case of National Movement of Recovered Companies
}

\author{
Natalia Vanesa Hirtz \\ Doutoranda em Sociologia (Université Libre de Bruxelles - Bélgica) \\ nhirtz@ulb.ac.be
}

\begin{abstract}
Resumen:
Este trabajo busca contribuir al conocimiento sobre las estrategias politicas que han sido empleadas por el Movimiento Nacional de Empresas Recuperadas (MNER); examinando las relaciones establecidas con el sistema político (gubernamental) y el empresariado nacional. Se indaga en que medida las oportunidades politicas llevaron al MNER a definir nuevas estrategias y su impacto sobre el movimiento. El análisis parte de la exploración documental de textos producidos por y sobre el MNER. Se realizaron entrevistas en profundidad a miembros de este movimiento. La acción colectiva de los trabajadores (de ocupación y recuperación de las empresas), contribuyó a la definición de nuevas oportunidades políticas y modificó la estructura política del MNER, contribuyendo a la extensión de estas oportunidades al empresariado nacional y al sistema gubernamental.
\end{abstract}

Palabras-clave: Gobernabilidad. Estrategias Políticas. Movimientos Sociales. Empresas Recuperadas. Autogestión.

\begin{abstract}
:
This work makes an attempt to understand the political strategies that are used by the National Movement of Reclaimed Enterprises (MNER); examining the relationships they established with the (governmental) political system and the national entrepreneurs. We examine to what degree the political opportunities were leading the MNER towards the definition of new strategies and their impact on the movement. The analysis starts from a documentary exploration of texts produced by and about the MNER; In-depth interviews were conducted with members and former members of the MNER. Collective action by workers (occupation and recovery of enterprises), contributed to the definition of new political opportunities and changed the political structure of the MNER, contributing to the extension of these opportunities to the national entrepreneurs and the Government.
\end{abstract}

Keywords: Governance. Political Strategies. Social Movements. Reclaimed Enterprises. Self-management.

Originais recebidos em: 23/06/11

Aceito para publicação em: 14/09/11

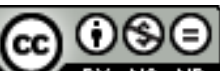

Comercial-Vedada a criação de obras derivadas 3.0 Unported License 


\section{Introducción ${ }^{1}$}

\section{Contexto general}

La reestructuración de la organización del trabajo y las consecuentes políticas de Estado implementadas durante la última etapa del siglo XX en Argentina, reforzaron drásticamente la precarización laboral y elevaron las tasas de desempleo.

La reforma del Estado y la reforma laboral implementadas durante el gobierno de Carlos Menem (1989-1999), significaron el desmoronamiento de la estabilidad laboral; la precarización en las condiciones de trabajo; el estancamiento y regresión de los salarios y altas tasas de desempleo. Situación mediada por la flexibilización laboral, el debilitamiento del poder de negociación sindical y la reducción de los impuestos patronales a las Obras Sociales (ETCHEMENDY, 1998).

En 1999, Fernando de la Rúa asume la presidencia después de una campaña que promete reactivación económica y desmantelamiento de la "corrupción" instalada. Sin embargo éstas expectativas no se concretaron, profundizando la deslegitimación del poder político, que no tardó en extenderse a las instituciones del sistema ya debilitadas.

Nace un nuevo ciclo de protesta que encuentra su máxima expresión en los enfrentamientos espontáneos del 19 y 20 de diciembre del 2001. Durante dos días la población tomó las calles con la consigna principal: "Que se vayan todos". El gobierno ordenó una feroz represión que provoco más de 35 muertos y múltiples detenciones. Pero la protesta no logró alcanzar un grado de organización que se tradujera en una alternativa política. De esta manera, la llegada al poder de Duhalde, como Presidente interino de la Nación (en febrero del 2002), marcó el momento descendente de la lucha y el comienzo del cierre del ciclo de protesta.

Durante el ciclo de protesta, los grupos piqueteros (movimiento de desempleados), las asambleas barriales, los clubes del trueque y las empresas recuperadas (ER) se convierten en el emblema de la lucha reivindicando "autogestión” y autonomía. Las demandas y las prácticas autogestionarias toman formas diferentes según la interpretación, las necesidades y las posibilidades concretas de cada agrupación. En general, estas

\footnotetext{
${ }^{1}$ Trabajo resultante de la tesis doctoral en curso: "Las empresas recuperadas en Argentina". Investigación desarrollada en la Universidad Libre de Bruselas.
} 
organizaciones se encuentran en ruptura con las estructuras "jerárquicas" tradicionales y focalizan su lucha hacia objetivos coyunturales, buscando efectivizar sus acciones en el corto y mediano plazo. Están relacionadas generalmente a luchas "locales", "concretas" que puedan llevar ya no "a la revolución" sino a "a pequeñas revoluciones en la vida cotidiana de cada uno". Son experiencias que nacen de alternativas puestas en marcha por algunos trabajadores, frente a la pérdida de las fuentes de ingreso o de trabajo estable que les permita "subsistir" (HIRTZ, 2004, p. 15). Se expresan en un tipo de organización y practicas "autónomas" de los partidos políticos y las organizaciones obreras; sin embargo en muchos casos los subsidios o ayudas estatales constituyen un recurso elemental para la subsistencia de éstas organizaciones que deben atender las necesidades de sus miembros.

Las primeras experiencias de ER surgen al finalizar los años '90. Frente a un proceso de liquidación o al anuncio del cierre de la empresa, los trabajadores deciden ocupar las instalaciones pero una vez que éste es inevitable, deciden ponerla en funcionamiento sin sus patrones.

Las ER surgen en contexto de luchas sociales y se multiplican frente a una crisis económica sin precedentes en Argentina. La mayoría de las empresas fueron recuperadas entre el 2001 y el 2003. Pero esta práctica sigue desarrollándose. El último relevamiento estadístico muestra un aumento más lento pero constante: en el 2003 se habían contabilizado 128 ER; en el 2004 eran 161 ER en las que trabajaban 6.900 personas; y en el 2010 se relevaron 205 ER que ocupaban a 9.362 trabajadores (RUGGERI, 2010, p 7-8).

\section{Marco conceptual y problematización}

Sidney Tarrow define el concepto de ciclo de protesta como:

una fase de intensificación de conflictos y de confrontación dentro del sistema social, que incluye una difusión rápida de la acción colectiva de los sectores más movilizados a los menos movilizados, un ritmo de innovación acelerada de las formas de confrontación, cuadros nuevos o transformados por la acción colectiva, una combinación de participación organizada y no organizada, y secuencias de interacción intensificada entre los disidentes y las autoridades que pueden terminar en la reforma, la represión y, a veces, en una revolución. (TARROW, 1997, p. 163-165).

Dentro de éste ciclo de protesta, las acciones colectivas pueden transformarse en movimiento social a partir del momento en que se elabora una estrategia política que 
orienta la protesta hacia el poder gubernamental. Los factores estructurales (económico/políticos) y coyunturales son según éste autor, determinantes para el desarrollo de estos movimientos. El conjunto de oportunidades politicas que se manifiestan según el contexto gubernamental en el que emergen los movimientos sociales puede contribuir o no a su desarrollo.

Tarrow, distingue cuatro tipos de oportunidades politicas: - la apertura del acceso al sistema político de los movimientos sociales; - la inestabilidad de las alineaciones políticas que se manifiestan principalmente durante los períodos electorales y que pueden empujar a las elites gubernamentales a buscar el apoyo de los grupos de protesta favoreciendo la coalición entre ambos actores; - la existencia de aliados a los movimientos sociales que tienen influencia dentro del sistema político - los conflictos y divisiones entre las elites políticas que pueden influenciar a una parte de esa elite a adoptar el rol de "defensores de las causas populares" con el objetivo de fortalecer su poder de influencia.

Según Tarrow, la acción colectiva puede contribuir a definir nuevas oportunidades politicas. De esta forma, un movimiento social puede ver cambiar su propia estructura de oportunidades gracias a su acción, pero al mismo tiempo puede también, contribuir a la extensión de oportunidades a otros grupos, tanto a sus opositores y a las elites que detentan el poder político-económico; los cuales se apropian de las causas de los contestatarios para posicionarse en tanto "defensores" de las causas del "pueblo".

Por otra parte, Chiapello y Boltanski (1999), nos aportan nuevos instrumentos que nos permiten distinguir la manera con la cual el capitalismo toma provecho de las críticas que le son dirigidas y se alimenta de ellas reintegrando y apropiándose de algunos de sus aspectos cuando éstas críticas "son incompletas", por lo que no atacan al sistema mismo sino a sus "disfuncionamientos", manteniendo ciertas afinidades con él. Estas afinidades están relacionadas al carácter contradictorio del capitalismo tanto como al carácter "incompleto" de las críticas que se le adjudican. Chiapello y Boltanski, retoman el análisis formulado por Castoriadis (1979) sobre el aspecto contradictorio del capitalismo. Este se basa sobre el hecho que el sistema capitalista no podría sobrevivir sin la reducción continua de los asalariados en simples ejecutores. Pero al mismo tiempo, solo puede funcionar en la medida en que esta reducción no se realiza; el capitalismo necesita la participación de los asalariados en el procesos de producción, participación que por otro lado tiende a 
imposibilitar (CHIAPELLO, BOLTANSKI, 1999, p. 678). Si el capitalismo toma provecho de ciertas críticas incompletas, efectuadas por movimientos sociales, es porque existe una cierta afinidad entre estas críticas y los valores vehiculizados por el sistema en un cierto momento histórico. El carácter incompleto de las críticas formuladas por ciertos movimientos sociales se basa en el hecho que existe una cierta afinidad con las representaciones dominantes del capitalismo.

El análisis de las representaciones dominantes del capitalismo actual así como de la estructura de oportunidades políticas y de las estrategias empleadas por el Movimiento Nacional de Empresas Recuperadas (MNER), nos permitirán comprender las relaciones que se establecen entre el régimen social vigente y las críticas formuladas por el MNER.

En la primera parte de este trabajo, se analizan los cambios operados en las políticas de los organismos financieros internacionales frente a la ineficacia de los programas formulados para los países endeudados de América Latina. Para lo cual se examinan las "Reformas de segunda generación" del Banco Mundial (BM). Por su impacto económico y social en América Latina, estas reformas vehiculan gran parte de las representaciones dominantes del capitalismo actual en América Latina.

En segundo lugar, se da cuenta de las estrategias del MNER destacando las relaciones establecidas con el sistema político (gubernamental); buscando indagar en que medida las oportunidades políticas llevaron al MNER a definir nuevas estrategias y su impacto sobre el movimiento. Se analizan las representaciones que el MNER comparte con las representaciones dominantes del capitalismo que, en este trabajo, personificamos en los organismos financieros internacionales.

\section{Algunas representaciones dominantes del capitalismo actual: democracia participativa, empowerment y autogestión}

Muchas de las políticas implementadas en América Latina a finales del siglo pasado, respondían a los programas de ajuste estructural elaborados por el Banco Mundial (BM). En Argentina, estas reformas fueron fuertemente implementadas durante los años

'90, provocando la pauperización de una gran parte de la población y creando un clima de bronca que dio origen a la abertura de un ciclo de protesta. 
La ineficacia constatada (en términos de desarrollo) de éstos programas de ajuste, es imputada por ésta institución, a las dificultades de implementación sobre el terreno. Debido a los impactos negativos, en 1997, el BM elaboró una "segunda etapa" de lo que debería ser la reforma del Estado en América Latina, la cual fue llamada: "Reformas de segunda generación". Según los especialistas del BM, si los programas de ajuste no dieron resultados positivos fue principalmente a causa de los obstáculos y resistencias de las organizaciones de esos países y más específicamente a la estructura de sus Estados (percibidos como burocráticos, intervencionistas, ineficaces y/o corrompidos). Para soslayar estos obstáculos, las Reformas de segunda generación proponen, entre otras cosas, fortalecer la "gobernabilidad" de estos países. Para ello, la "democracia representativa", deslegitimada, debe ser completada por la "democracia participativa" y por el "empowerment" de la sociedad civil (MANOR, 1999). De esta forma, si la ineficacia de los programas de ajuste se deben a la intervención, la burocracia y la ineficacia de los Estados; la sociedad civil, debe "organizarse" y participar "eficazmente" de su destino.

Una de las recetas más repetidas por el BM, impulsa "el desarrollo de redes comunitarias locales, con el objetivo de generar nuevas formas de participación ciudadana y estrategias de empowerment de los sectores más vulnerables" (SVAMPA, 2005). Así uno de las funciones especificas que se le atribuye a las organizaciones de la sociedad civil es la de "liberar al Estado y las empresas de ciertas cargas sociales", por lo que una parte creciente de servicios sociales es confiada a estas agrupaciones "autogestionadas". De esta forma el Estado se deshace de ciertas responsabilidades sociales, que pasan a ser de competencia de la sociedad civil. (VINOKUR, 2002). En Argentina estas políticas se reflejaron fuertemente durante los últimos años con el fomento de microemprendimientos y cooperativas que brindaron un paliativo para los sectores más vulnerables sin necesidad de depender de la provisión de los recursos estatales. Así, “entre 1994 y 2004, se crearon más de 12.000 cooperativas" (GARCÍA, 2006).

\section{Las empresas recuperadas por sus trabajadores}

Las primeras experiencias de ER, surgen de manera aislada de otros movimientos sociales, a principios de los años '90. A finales del 2001, estas experiencias se multiplican 
rápidamente y sus trabajadores comienzan a coordinar sus luchas. De manera general, el proceso de recuperación de las empresas se desarrolla a partir de la ocupación de la planta para exigir el pago de salarios e impedir la liquidación de la empresa. Los empresarios no responden a éstos reclamos y optan por no regresar a la planta, algunos declaran la quiebra, otros llaman a lock out o comunican la suspensión de la producción durante un tiempo determinado. La ocupación puede durar varios meses sin que se encuentre una solución a las demandas de los trabajadores. Mientras tanto éstos no tienen acceso a salarios ni indemnizaciones por despido, situación que los lleva a relanzar la producción de la empresa para poder hacer frente a sus necesidades de subsistencia.

En su inicio la lucha de los trabajadores no apunta al control de la producción sino a la protección de sus fuentes de ingreso. Sin embargo, el proceso desarrollado para lograr este objetivo los induce a tomar en sus manos el control de la producción. Esta acción implica la confrontación directa con los sectores empresariales y ataca (en la práctica) a la propiedad privada.

Durante el proceso de lucha contra el cierre de la empresa, su ocupación y puesta en funcionamiento, se crearán nuevas solidaridades entre trabajadores y se forjarán formas de organización más horizontales. Al retomar la producción de la empresa los trabajadores la gestionarán y organizarán el trabajo empleando los mismos métodos que aprendieron en la lucha: la discusión y la toma de decisiones mediante la asamblea general. El proceso de recuperación induce no solo a la creación de formas de organización más horizontales sino que también implica un avance en el cuestionamiento de la propiedad privada y favorece la construcción de solidaridades; en un contexto en que las nuevas formas de organización del trabajo introducen mecanismos de competencia, promoviendo estrategias y vivencias profundamente individualistas.

Sin embargo, los trabajadores no pueden hacer funcionar estas empresas por mucho tiempo sin encontrar una cobertura legal. La creación del MNER y de la Coordinadora de fábricas ocupadas y trabajadores en lucha, marcaron dos estrategias diferentes para responder a ésta situación: el MNER reivindica la expropiación de la empresa por el Estado y donación en comodato a los trabajadores previamente conformados en cooperativa de trabajo; mientras que la Coordinadora de fábricas ocupadas, reclama la estatización bajo control obrero. 
Por su trayectoria y sus múltiples influencias políticas, es el MNER quien construyó el tipo de estrategia dominante en la recuperación de empresas. Esta estrategia consiste en conformar una cooperativa y exigir al gobierno, la expropiación de la empresa y su donación a la cooperativa. En un principio, el MNER exigía la expropiación sin pago de indemnizaciones a los antiguos propietarios de la fábrica pero, en la práctica, los trabajadores debieron aceptar y asumir el pago de estas indemnizaciones para poder acceder a la expropiación. Sin embargo muchas ER no han sido expropiadas ( $37 \%$ de las ER) y sus trabajadores deben recurrir a alternativas jurídicas transitorias mientras esperan la expropiación. El 63\% de las ER obtuvieron la expropiación de la empresa pero solo el 19\% de ellas fueron expropiadas definitivamente, mientras que el $81 \%$ de las expropiaciones son temporarias, por lo cual los trabajadores deben movilizarse para obtener la renovación de la expropiación cada dos años (RUGGERI, 2020, p 23).

\section{Desarrollo de la estructura de oportunidades políticas del MNER}

Durante el año 2001, la recuperación de empresas se multiplican y los trabajadores comienzan a coordinar acciones. En octubre de ese año, los obreros de la ER IMPA ${ }^{2}$ convocan a una reunión en la que participaron tanto ER como también la Federación de Cooperativas Portuarias, la Unión de Trabajadores Desocupados de Santa Fe y la Federación de Cooperativas de Trabajo. El objetivo de esta reunión era conformar un movimiento que apuntara a encontrar una solución jurídica para las ER, reforzarlas económicamente y favorecer la multiplicación de estas experiencias. Buscando también reforzar el desarrollo de una economía solidaria. ${ }^{3}$

De éste encuentro surgirá el MNER conformado por la mayoría de las ER presentes. El objetivo consistía en integrar todas las iniciativas de recuperación sin importar las formas societarias que éstas adoptaran. La prioridad se puso "en la recuperación de las empresas. Considerando que la conformación en cooperativa es un medio necesario para la recuperación pero no un fin en si mismo" (ENTREVISTA..., 2004). Por este motivo deciden constituir un movimiento específico, por fuera de las federaciones de cooperativas.

\footnotetext{
${ }^{2}$ La metalúrgica IMPA, fue una de las primeras ER por sus trabajadores en el país.

${ }^{3}$ Véase el "Acta de reunión” reproducida en Rebón. J., (2004, p. 144-146).

Em Debat: Rev. Dig., ISSNe 1980-3532, Florianópolis, n. 6, p. 153-170, jul-dez, 2011.
} 
El MNER se conforma con el objetivo de integrar las diversas iniciativas de recuperación de fábricas y empresas del país. La constitución política de la dirección de este movimiento, en su origen, expresa una alianza peronista entre los sectores más progresistas y los más conservadores de ésta corriente. Los objetivos principales eran: recuperar las fuentes de trabajo, fomentar el desarrollo de la economía social y de la producción nacional. Reivindicaciones compartidas tanto por la derecha peronista, representada por la figura de Luís Caro (abogado y dirigente del MNER), como por la fracción identificada al peronismo de izquierda y representada por las figuras de Eduardo Murúa y Guillermo Robledo; quienes habían participado como delegados sindicales en algunos intentos de recuperación de empresas durante los años '80. Tenían como objetivo "preservar el parque industrial frente a la apertura económica del radicalismo". Esperaban " las elecciones presidenciales del ' 89 ", convencidos de que " la llegada al poder de Carlos Menem iba a implementar una política de economía industrial.” (ENTREVISTA..., 2004). Ésta alianza entre peronistas de "derecha" y de "izquierda" no perdurará mucho tiempo. En el 2003, una fracción de ER, dirigida por Luís Caro, conforma su propio movimiento, el MNFR.

El término "recuperación" proviene del MNER, concepto dominante hoy en día para referirse a este proceso, que significa para el MNER el "salvataje de la producción, del empleo y de la dignidad de los trabajadores". Orientando la política hacia intereses de índole "nacionales y populares". (MNER, 2003). Así, la recuperación de las empresas apunta a defender "la soberanía nacional" ya que se trata de " una producción nacional que apunta a que los frutos se queden en el país" (ENTREVISTA..., 2004).

La prioridad está puesta en la recuperación de: fuentes de trabajo y de la economía nacional. Estas prioridades llevarán en el 2003, al MNER a integrar la Coordinadora de Acción Productiva (CAP), junto a representantes de pyme y de emprendimientos rurales con el "objetivo de defender el rol protagónico de las pequeñas unidades productivas en la Argentina que viene" (DELLATORRE, 2003). Esta alianza, responde a la estrategia de conformar un grupo de presión que pueda "imponer sus condiciones" al nuevo Gobierno Nacional. El pronunciamiento de dicha Coordinadora se dio a conocer en momentos posteriores al pronunciamiento de los resultados de las elecciones presidenciales de 2003, que daban como presidente electo a Néstor Kirchner. 
Julio César Urien, integrante del MNER y representante de la CAP, define los objetivos centrales de ésta Coordinadora como: la exigencia que el Estado desenvuelva un "rol activo [...] en la reactivación económica", que fije "la prioridad en el desarrollo del mercado interno", en el "desarrollo de las economías regionales que vigorice las cadenas de valor e impulse las exportaciones con valor agregado", y que haga "hincapié en el Mercosur como estrategia comercial y de integración”, oponiéndose a la conformación del ALCA, el cual terminaría de "arruinar" la situación de las pyme nacionales. Urien, termina su exposición apuntando sus objetivos en términos de la clase social a la cual representa.

Somos una burguesía con conciencia nacional, hemos decidido poner todos los esfuerzos en articular este espacio impulsando la formación de la CAP [...]. El Movimiento de Empresas Recuperadas también participa y las contradicciones que podemos tener con ellos, como empresarios y trabajadores, son secundarias (DELLATORRE, 2003).

Guillermo Robledo, uno de los dirigentes del MNER, identificando la lucha del movimiento a ciertas reivindicaciones del sector empresarial nacional, argumenta la necesidad que el nuevo Gobierno Nacional tome

medidas rápidas para recuperar la producción; las pymes no pueden seguir atrapadas en el sistema de calificación de créditos del Banco Central, que les impide acceder al préstamo bancario [...] impulsamos la formación de fondos fiduciarios por sector, administrados en forma conjunta por el Estado y los sectores productivos, y un urgente plan de refinanciación de pasivos, recuperación del mercado interno redistribuyendo ingresos, aumentando salarios y bajando impuestos al consumo, y modificar la Ley de Quiebras" (DELLATORRE, 2003).

El CAP no perduró. Sin embargo, el discurso y las reivindicaciones de los dirigentes del MNER, frente a la conformación de esta Coordinadora, expresan un cambio cualitativo en la política del movimiento. La estructura política del movimiento se modifica, contribuyendo a la extensión de oportunidades al empresariado nacional ya que orienta las reivindicaciones hacia la defensa de la propiedad privada de los pequeños y medianos empresarios. Así, el "conflicto" que confrontaba de manera antagónica a trabajadores de pyme con sus empresarios, se disuelve en una alianza orientada hacia el restablecimiento de un orden marcado por la "armonía social", en donde el antagonismo de clase se diluye en la "defensa de la producción nacional".

La oportunidad planteada por la inestabilidad política en el 2003, durante las elecciones presidenciales, es percibida por el MNER como el momento propicio para crear una fuerza heterogénea que pueda influenciar a un nuevo gobierno, que busque fortalecer 
su poder, y adoptar sus reivindicaciones. Así, en pleno período electoral, la CAP organiza una conferencia de prensa para declarar su "apoyo incondicional" al futuro presidente Néstor Kirchner. (CAMINO..., 2003).

Entre tanto, los dirigentes del MNER, buscan tejer otras alianzas políticas para consolidar sus fuerzas accediendo al poder gubernamental. Las elecciones presidenciales se llevan a cabo en un contexto en el que el sistema político se encuentra en un momento de deslegitimación social. Por lo tanto, el nievo gobierno buscará el apoyo de ciertos grupos de protestas con el fin de garantizarse una segura estabilidad social para consolidar la legitimidad de su poder. Aprovechando el período electoral, en el que se abren nuevas oportunidades políticas, el MNER no solo intenta encontrar aliados dentro del sistema político y económico sino que también busca ocupar un espacio dentro del sistema gubernamental, postulando para las elecciones a sus dirigentes.

Durante las elecciones porteñas del 2003, Eduardo Murúa, presidente en ese momento del MNER, se postula para diputado bonaerense del "Polo Social". También, José Córdoba se postula para la intendencia en Florencio Varela (Provincia de Buenos Aires) y Francisco "Barba" Gutiérrez se presenta bajo éste mismo partido para la gobernación, sin lograr los votos necesarios. Sin embargo éste último, en el 2005, se presentará con el Frente Para la Victoria (partido político conformado por Néstor Kirchner) obteniendo una banca como diputado nacional. Entre tanto, otro dirigente del MNER, Diego Kravetz, encabeza la lista de candidatos a la legislatura para las elecciones de la Ciudad de Buenos Aires dentro del "Partido de la Revolución Democrática" (partido que apoyará a nivel nacional al Frente Para la Victoria) obteniendo una banca. Otro de los dirigentes del MNER, era José Abelli quien se postula en el 2003, como diputado por la provincia de Santa Fe por "Encuentro Progresista", partido que apoya a la lista del gobernador de esta provincia, Hermes Binner. Abelli es conocido en Rosario por su participación durante los años '90, en la conformación de "cooperativas de trabajadores sin empleo". Estas fueron creadas a partir de las privatizaciones de las vías ferroviarias por los ex-empleados estatales. De este modo se intentó liberar a las privatizadas de las responsabilidades contractuales de esa fuerza de trabajo, lo cual contribuyó a una fuerte precarización de estos trabajadores, quienes dejaron de disponer de obra social y de un salario fijo y, en su gran mayoría, terminaron cerrando sus cooperativas. 
La estrategia electoral de quienes fueron dirigentes máximos del MNER, no implica la conformación de un proyecto político a la interna del movimiento. La intensión es de participar dentro de los partidos oficiales con el fin de influenciar sus orientaciones respecto al porvenir de las ER y la industria nacional.

Por su parte, las autoridades políticas muestran un cierto grado de apertura hacia éstos procesos de recuperación, especialmente el Gobierno de la Ciudad de Buenos Aires, distrito en el cual se llevaron a cabo la mayoría de las expropiaciones de empresas por las que los trabajadores deberán pagar la indemnización. Este apoyo no implicó costos políticos ni económicos para el Gobierno. Es más, en un contexto en el cual las autoridades políticas debían restablecer su legitimidad, la apertura hacia ciertos movimientos sociales les abre nuevas oportunidades políticas para consolidar su fuerza.

Contrariamente, frente a los procesos de lucha llevados a cabo por otras ER (que integraban la Coordinadora de fábricas ocupadas), que ponían en cuestionamiento al Estado, la propiedad privada o que exigían la estatización de la fábrica "bajo control obrero", el Gobierno mostró una gran hostilidad y las luchas de éstos trabajadores fueron rápidamente reprimidas por las fuerzas policiales. El caso emblemático de esta lucha, en la Ciudad de Buenos Aires, fue la de las trabajadoras de la fábrica textil Brukman, quienes fueron desalojadas del inmueble en el 2003. Las trabajadoras reivindicaban la estatización bajo control obrero de la fábrica. El Gobierno de la Ciudad de Buenos Aires, argumentó el rechazo de esta exigencia considerando que las "cargas fiscales" que esto demandaría no se apoyaban "en argumentos que muestren el carácter estratégico que reviste el mismo" siendo

imposible encontrar argumentos cuantitativos (capacidad de producción, dotación del personal, producción que "arrastra" de los sectores proveedores, entre otros) ni de tipo cualitativo (singularidad del producto o capacidades de procesos, entre otros) que brinden elementos a favor de una decisión en ese sentido (BRINER y CUSMANO, 2003, p. 90-91).

En síntesis para el Gobierno de la Ciudad, Brukman, como podría ser cualquier otro microemprendimiento o ER, no representaba un "negocio rentable". Su estatización necesitaría la provisión de recursos estatales, por lo que se supone que Brukman daría pérdidas. Cómo puede pretender entonces, ese mismo Gobierno, que creando una Cooperativa estas trabajadoras puedan llegar a obtener ganancias necesarias para sostener no solo sus necesidades básicas sino también el pago de la indemnización de expropiación? 
Al abrir una alternativa legal que permite recuperar las empresas, por medio de la expropiación y donación mediante el pago de las indemnizaciones a los trabajadores organizados en cooperativa, el Estado institucionaliza ciertas formas de accionar para recuperar une empresa, al mismo tiempo que reprime severamente otro tipo de acciones que no sean la establecidas.

\section{La buena gobernabilidad y la fracción del MNER}

El gobierno responde a una "política de buena gobernabilidad", fortaleciendo el empowerment de los trabajadores para su "autogestión”, que desligue, al mismo tiempo, al Estado de una gran parte de sus "responsabilidades sociales". Un ejemplo contundente sobre esta política se puede leer en el informe realizado por la Secretaría de Desarrollo de Económico del Gobierno de la Ciudad de Buenos Aires en 2003. En este texto, se rescatan los rasgos positivos de las empresas legalmente recuperadas ya que

desde el punto de vista del Gobierno de la Ciudad de Buenos Aires, [...] la totalidad de las erogaciones realizadas como resultado de las declaraciones de utilidad pública de las ocupaciones temporarias y expropiaciones, [...] son inferiores al costo de atender la situación de los trabajadores y las personas a su cargo mediante asistencia alimenticia y subsidios por desempleo (BRINER y CUSMANO, 2003, p. 95).

Así mismo, el apoyo que las autoridades políticas pueden brindar al emprendimiento de ER, muestra sus límites frente a ciertas exigencias financieras que éstas puedan reclamar. En el 2005, por ejemplo, los trabajadores de IMPA (metalúrgica recuperada en la cual se fundó el MNER) se movilizaron para exigir al Gobierno de la Nación la obtención de un crédito a través del Banco de la Nación. Eduardo Murúa, Presidente de ésta ER (y del MNER) y Guillermo Robledo, Vice-Presidente de IMPA, decidieron sobrepasar los canales institucionales establecidos con el Poder Nacional llamando a la movilización contra las políticas de un Gobierno en las que múltiples miembros del MNER participaban o estaban fuertemente vinculados. Este hecho, desencadenó una fuerte acentuación de las divergencias en el seno del movimiento sobre las formas de relacionarse con el Gobierno. Llevando a la fragmentación del movimiento y marginando a aquellos dirigentes que habiendo fortalecido la institucionalización de la 
lucha abierta por los trabajadores de las ER, intentaron oponerse a las nuevas condiciones establecidas.

Actualmente, algunos pequeños grupos de ER siguen usufructuando el nombre de un movimiento que tiende a desaparecer, mientras que la mayoría de las empresas que lo constituían, conformaron, en diciembre del 2006, la Federación Argentina de Cooperativas de Trabajadores Autogestionados (FACTA), con el objetivo de

unir a un sector de la economía, en la cual las ER son parte integrante pero no es todo. Hay emprendimientos sociales, cooperativas de trabajo, las cuales tiene que agruparse en un movimiento más amplio. La idea es la de comenzar a plantear un gran movimiento de economía social en donde FACTA sea un actor más [...] Queremos tener una personería jurídica porque creemos que hay que presentarse ante las autoridades tanto nacionales como internacionales de manera un poco más prolija. Una personería jurídica nos va a permitir no solo a firmar convenios y alcanzar algunos acuerdos con organismos nacionales e internacionales, sino que además nos presentamos ante las autoridades como una organización. (ENTREVISTA..., 2007).

De esta forma, ya no solo el proceso de lucha de los trabajadores se disuelve en el proyecto de ER sino que éstas se diluyen en un proyecto "cooperativista y autogestionado". Así la declaración de principios de ésta nueva Federación concluye su presentación diferenciándose de las luchas que dieron origen al MNER: "porque no somos parte de lo que fue sino de lo que será". (DECLARACIÓN..., s/d).

En lo que respecta a la realidad actual de los trabajadores que llevaron a cabo una lucha dinámica enfrentándose al orden establecido, el sostenimiento de sus empresas los lleva, en muchos casos, a tener que acudir al trabajo a façon, ${ }^{4}$ a deber aumentar el tiempo de jornada laboral y/o el ritmo de trabajo para poder responder a las demandas del mercado. En el 2010, 49,5\% de las ER trabajaban a façon. Para muchas ER, en un premier momento, esta modalidad de trabajo permite relanzar la producción pero al mismo tiempo, es muy poco rentable para los trabajadores y representa la "existencia de lo que podríamos llamar un patrón externo" (RUGGERI, 2020, p. 33-34). La baja rentabilidad del trabajo a façon, conduce a deber aumentar el nivel de producción para poder enfrentar las necesidades económicas de la cooperativa y de sus trabajadores. En síntesis, el proceso de lucha de un inicio pasa a ser, en muchos casos, una lucha por la sobrevivencia de la cooperativa dentro del mercado capitalista.

\footnotetext{
${ }^{4}$ El trabajo a façon consiste en la venta de la mano de obra (de los trabajadores de las ER) a una empresa que se encarga de poner a disposición los insumos necesarios a la producción y que comercializa lo producido.

Em Debat: Rev. Dig., ISSNe 1980-3532, Florianópolis, n. 6, p. 153-170, jul-dez, 2011.
} 


\section{Conclusión}

La acción colectiva llevada a cabo por los trabajadores dentro de las empresas en las que eran asalariados forjó, en un contexto de crisis social y política (ciclo de protesta), una nueva relación de fuerzas que les permitió profundizar el proceso de ocupación de sus empresas y relanzar su producción. Sin embargo, una vez estabilizada la situación política, social y económica que dio inicio al conflicto $\mathrm{y}$, satisfechas las demandas principales de los trabajadores con el otorgamiento de alguna cobertura legal que les permitía resguardar sus fuentes de trabajo, se institucionalizan las formas de lucha otorgando legalidad al modo en que los trabajadores pueden o no llevar adelante éste proceso.

Cerrado el ciclo de protesta, el orden social es restablecido una vez institucionalizadas las formas de lucha que habían puesto en cuestionamiento los canales convencionales de protesta. De esta forma, el nuevo gobierno logra retroalimentarse de las críticas sociales vehiculizadas por el MNER, fortaleciéndose frente al malestar social producido por el carácter de exclusión y explotación propio al capitalismo.

Las críticas planteadas por el MNER hacia el orden establecido, hacían referencia a sus disfuncionamientos coyunturales y no a la esencia misma de ese orden, en otras palabras, no se cuestionaban las relaciones sociales de producción. Es este carácter "incompleto" de las críticas atribuidas a un orden instituido que permiten a éste incorporar y apropiarse ciertos aspectos.

Ciertas reivindicaciones del MNER tuvieron impacto en el sistema jurídico-político. La propuesta del MNER y adoptada por el Gobierno, reconoce a los trabajadores que conforman una cooperativa y aceptan pagar la indemnización de la expropiación de la empresa, al mismo tiempo que niega la posibilidad de desarrollo de otro tipo de experiencias que signifiquen aportes económicos del Estado con autonomía de los trabajadores.

En síntesis, la acción colectiva de los trabajadores, que comenzó como un modo de "protesta" hacia los sectores empresariales y que atacaba (en la práctica) a la propiedad privada, contribuyó a la definición de nuevas oportunidades políticas: la conformación legal de las ER, facilitada por estrategias políticas y legales como la aplicación de leyes de 
expropiación. Las estructuras políticas del movimiento se modificaron, contribuyendo a la extensión de oportunidades a las élites gubernamentales y al empresariado nacional (ya que orienta las reivindicaciones hacia la defensa de la propiedad privada de los pequeños y medianos empresarios). Así, el conflicto que confrontaba de manera antagónica a trabajadores (de pyme) con sus empresarios y el estado (en tanto que institución protectora del "derecho" a la propiedad privado), se disuelve en una alianza orientada hacia el restablecimiento de un orden marcado por la "armonía social", en donde el antagonismo de clase se diluye en la "defensa de la producción nacional".

\section{Bibliografía}

BOLTANSKI, Luc y CHIAPELLO, Eve. Le nouvel esprit du capitalisme. Paris: Gallimard, 1999. p. 843

BRINER, María Agustina y CUSMANO, Adriana. "Las empresas recuperadas en la Ciudad, a partir del estudio de siete experiencias". In: Empresas Recuperadas. Ciudad de Buenos Aires. Buenos Aires. Buenos Aires: Secretaría de Desarrollo Económico del gobierno de la Ciudad de Buenos Aires, 2003, p. 21-83.

CAFARDO, Analía y DOMÍNGUEZ FONT, Paula. Autogestión obrera en el siglo XXI. Cambios en la subjetividad de los trabajadores de empresas recuperadas, el cambio hacia una nueva sociedad. Buenos Aires: Centro Cultural de la Cooperación, Cuaderno de trabajo $\mathrm{n}^{\circ} 27$, octubre 2003. p. 71

CAMINO a un modelo productivo. Respaldo de las pyme a Kirchner. La Nación, 15 may.2003.

DECLARACIÓN de principios y objetivos de la federación argentina de cooperativas de trabajadores autogestionados. In: Agencia de noticias de los trabajadores de empresas recuperadas. s/d.

ECHAIDE, Javier. Debate sobre Empresas recuperadas. Un aporte desde lo legal, lo jurídico y lo político. Buenos Aires: Centro Cultural de la Cooperación, Cuaderno de trabajo $\mathrm{n}^{\circ}$ 25. Mayo 2004. p. 100. 
ENTREVISTA realizada a Fabio Resino, Vice-Presidente de FACTA. Abril 2007.

ENTREVISTA realizada a Ignacio Saavedra, ex-miembro del MNER. Diciembre, 2004.

ETCHEMENDY, Sebastián y PALERMO, Vicente. Conflicto y concertación. Gobierno, congreso y organizaciones de interés en la reforma laboral del primer gobierno de Menem (1989-1995). Desarrollo económico, Buenos Aires: enero/marzo, 1998, vol. 37, n 148, p. 559-590.

GARCÍA, Alejandro. Manual de economía popular. Cuando la solidaridad es una cuestión de pobres. Buenos Aires: Punto de Encuentro, 2006.

HIRTZ, Natalia, Genre et participation social. Étude sur la population étudiante de l'Université Nationale de Córdoba (Argentine). Trabajo final de post-master en Ciencias Sociales: Sociología y Antropología, Université Libre de Bruxelles, Université Catholique de Louvain, Facultés Universitaires Saint Louis. Bruselas, 2004.

LAVACA. Sin patrón: fábricas y empresas recuperadas por sus trabajadores. Una historia, una guía. Buenos Aires. Lavaca Editora, 2004. p. 302.

MAGNANI, Esteban, El cambio silencioso. Empresas y fabricas recuperadas por los trabajadores en la Argentina, Buenos Aires. Prometeo libros, 2003. p. 230.

MANOR, James. Civil Society and Governance: A Concept Paper. Working paper, Institute of Development Studies, University of Sussex, 26 august 1999.

MNER. Propuesta del MNER al gobierno nacional. Para no perder un puesto de trabajo más, 2003.

REBÓN, Julián. Desobedeciendo al desempleo. La experiencia de las empresas recuperadas. Cuaderno de trabajo $\mathrm{N}^{\circ}$ 2. Buenos Aires. Picaso/La rosa blindada, 2004. p. 167.

RUGGERI, ANDRÉS et all. (Dir.) Las empresas recuperadas en la Argentina. 2010. Informe del Tercer Relevamiento de empresas recuperadas por sus trabajadores del 
Programa Facultad Abierta. SEUBE-Facultad de Filosofía y Letras de la Universidad de Buenos Aires. Buenos Aires. 2004. p 100.

SVAMPA, Maristella, La sociedad excluyente. La Argentina bajo el signo del neoliberalismo, Buenos Aires. Taurus, 2005. p. 346.

TARROW, Sidney. El poder en movimiento, Barcelona. Alianza, 1997. p. 352 (Ed. original, Power in movement: social movements, collective action and politics, Cambridge University Press, Cambridge, 1994).

VINOKUR Annie, L'enseignement supérieur en question. In: Coloquio del Réseau d'Étude sur l'Enseignement Supérieur (RESUP), L'université en question, Bordeaux, 16 y 17 may. 2002. 